obituary

\section{A. J. Haagen-Smit}

THE FIELD of air pollution lost one of its most vocal and colourful workers when Professor A. J. Haagen-Smit died on 17 March 1977 of cancer in Pasadena, California.

The objective facts are that Arie Jan Haagen-Smit was born in 1900 in Utrecht, Holland, and obtained his B.A., M.A., and Ph.D. from the University of that city, obtaining the last degree in 1928. After obtaining his doctorate, he was successively head assistant in organic chemistry and lecturer until 1936, when he went to the U.S. as a lecturer in biological chemistry at Harvard, spending the 1936-37 academic year there. In 1937 he joined the faculty at the California Institute of Technology as an associate professor, as a part of a conversion of that institution from a local trade school to its present level of excellence, begun under the late Dr Robert Millikan. Haagen-Smit retired at CalTech in 1971 as Professor of Biochemistry. $\mathrm{He}$ also served as executive officer of the department of biochemistry and director of the excellent plant environment laboratory there.

His early research interests were in natural products, particularly essential oils, although he made major contributions to the chemistry of plant alkaloids, plant hormones, and the chemistry of microorganisms. Towards the end of World War II, the Los Angeles area began to experience an increased incidence of haze, accompanied by eye irritation and damage to plants. In the late 1940s this had become a sufficiently frequent occurrence to generate public pressure for its abatement, and it was promptly termed "smog" by some supposed analogy to the more venerable phenomenon then characteristic of London. A sizeable effort was made, derived from this analogy, to control emissions of sulphur dioxide in the area. If anything, the situation got worse.

Concerning the events that followed, Haagen-Smit himself subsequently told several stories. I am personally inclined to credit the one he told me when I first met him, in the mid-1950s. Remember that he was particularly concerned with essential oils, and therefore had a very highly trained nose. $\mathrm{He}$ said that the current explanation (that it was all a matter of sulphur emissions) did not fit with what he smelled on a smoggy day, which was much more reminiscent of oxygenated organic compounds. One day he was leafing through some back copies of Chemical Abstracts, and chanced upon a report of a Swiss patent from, if memory serves me correctly, the late 1930s. This patent claimed a process for producing mixed oxygenated compounds from hydrocarbons by photolysis in the presence of nitrogen dioxide. $\mathrm{He}$ immediately set up a benchtop experiment with some nitrogen dioxide and a bit of 3-methylheptane, and exposed it to a conveniently available ultraviolet light. After a time, he sniffed the resulting brew, and found that the odour closely resembled that of the outdoors air on the same smoggy day. I remember chuckling with him over the question of whether the holder of the Swiss patent should sue the City of Los Angeles for infringement.

Given these facts, it was obvious to Haagen-Smit that the source of Los Angeles pollution was primarily the automobile and secondarily the petroleum refineries that are interspersed throughout the city. (In fact, I have heard it theorised that the initial wartime problem stemmed from the injudicious selection of a site for a plant to manufacture butadiene, a key ingredient in synthetic rubber.) Needless to say, Haagen-Smit was violently attacked. He had shown that ozone was one of the products of the photochemical reaction. Some of the local industries heavily sponsored a local eccentric who purported to have data showing that the ozone was all of natural origin. Industry also funded local research institutions in the construction of rather elaborate laboratory facilities specifically for the purpose of disproving his theory. An elaborate superstructure, the Air Pollution Foundation, was set up to administer these early contracts. Techniques and instruments were devised or adapted for the measurement of a number of the key ingredients in the Los Angeles atmosphere, and these were produced commercially by local scientific instrument makers, particularly by the Beckman Instrument Company. It is probably no exaggeration to say that modern atmospheric chemistry was born from the researches of HaagenSmit and of those hired by the affected industries to refute him. While there were a few details needing correction, the sole result of the studies was to support Haagen-Smit's orginal theory.

Once the issue was settled by the acquisition of further knowledge, Haagen-Smit received numerous appointments, honours, and awards. He served for a time as chairman of the California Air Resources Board and of the U.S. President's Task Force on Air Pollution, as well as serving as a member of numerous other committees. He worked briefly as a consultant for Southern California Edison, and had a signal role in the development of the technique of reducing nitrogen oxide emissions from power plants by two-stage combustion. $\mathrm{He}$ was founding editor of the International Journal of Air Pollution, but found the work uncongenial and passed the job on to me at the end of the first year. Nevertheless, he served on the Editorial Advisory Board until last year, through two metamorphoses; the journal is now called Atmospheric Environment. Honours included membership in the National Academy of Science and receipt of the Los Angeles County Clean Air Award, the Chambers Award of the Air Pollution Control Association, the Hodgkins Medal of the Smithsonian Institution, the B. Y. Morrison Award of the U.S. Department of Agriculture, the Honor Scroll of the American Institute of Chemists, the Fritzsche Award and the Award for Pollution Control of the American Chemical Society, the Cottrell Award of the Research Corporation of America, the John and Alice Tyler Ecology Award of Pepperdine University, and the National Medal of Science. In his native country he was made Laureate of Labour by the Netherland Chemical Society, and he was made Knight of the Order of Orange Nassau. It is almost unnecessary to add that he belonged to a lengthy list of appropriate professional societies.

However, it is not for his honours that his many colleagues throughout the world will remember. "Haagy." Rather we will remember him for his warm humanity, his unflagging humour and his scientific insight. It would be a signal service to the science historians of the future if someone could take the time and the trouble to begin collecting anecdotes of the man. It is perhaps illustrative of his essential humility that I have found it necessary to consult a half dozen biographical sources to compile the above list of 
honours; he rated them sufficiently unimportant that he seems to have given no one source the complete list.

A couple of years ago a joke made the rounds in which God's intent to create heaven and earth was completely thwarted by a demand from the Heavenly Environmental Protection Agency that he first file an environmental impact statement. As I fell asleep the night after learning of Haagy's death, that story suddenly returned to me with the thought, "He's got some help; now Creation can proceed!"

\section{James $P$. Lodge}

\section{Donald Reid}

Donald Reid, Professor of Epidemiology at the London School of Hygiene and Tropical Medicine, died suddenly of a heart attack on March 26 at the age of 62 . His standing as an epidemiologist had few equals, in Britain or in the world.

$\mathrm{He}$ was born in a small Scottish fishing village, the son of a Post Office linesman. The family was poor and survived only through his mother's courage and prudent housekeeping. In later life he still preferred a bus to a taxi, and in research he would think long and hard about efficient study design, and how to salvage something if the primary aim were to be frustrated. If "plan A" failed, he always had "plan B" ready.

After qualifying in medicine he entered RAF Bomber Command in 1939 , and there laid the foundations of his own career and of psychiatric epidemiology by analysing the relation between stress and neurotic illness. $\mathrm{He}$ showed that breakdown correlated highly with current casualty rates in a particular unit, but not at all with total flying hours. After the war he joined Bradford Hill at the London School of Hygiene and Tropical Medicine, and he succeeded him on his retirement in 1961. In a discipline where data are largely observational and often of poor quality he practised and taught scepticism and meticulous accuracy; but where others discounted the research potential of vital statistics, or surveys using crude clinical examination techniques, he showed that even inferior data can be valuable provided that their errors are recognised and quantified.

Most of his work was in relation to respiratory disease, later extending also to cardiovascular problems. Using national sickness-absence data for postal workers he showed the importance for bronchitis of exposure to air pollution: an excess in absence rates in areas with higher fog frequency was specific for bronchitis and for out- door workers. By similar methods he identified the tuberculosis hazard for workers in bacteriology laboratories and mortuaries. He was a leading contributor to our recognition of the effects on health of cigarette smoking, demonstrating its interactions with air pollution in the causation of bronchitis, and with other coronary risk factors in the occurrence of heart attacks. He was particularly delighted by his recent election as an honorary fellow of the American College of Cardiology, and at the time of his own death he was working on the predictors of death from coronary heart disease.

His reputation stood as high overseas as at home. His international studies of migrants compared their disease rates with those of their native-born contemporaries in the host country and their siblings at home, thus permitting separation of gentic and environmental influences. He had friends in almost every country, and was much in demand as lecturer, chairman and consultant. Many may have thought that his talks and opinions were given impromptu, but in fact they were always meticulously prepared. Similarly his confident and optimistic manner of belied painful inner self-questioning and nervousness.

His colleagues and students will remember him for his humour (often directed against himself), his warmth and unlimited concern with their wellbeing, and his complete public and private integrity. He leaves his wife and two daughters; and countless friends in many countries.

\section{Geoffrey Rose}

\section{S. Vallarta}

Dr Manuel Sandoval Vallarta died on April 18 in Mexico at the age of 78 after a long and distinguished career. He was particularly well known for his theoretical work on the geomagnetic effects on cosmic rays.

Together with the late Abbé Lemaitre, Vallarta solved to first order the problem of the cosmic ray intensity distribution in the geomagnetic field. This was done in two stages. First, the "allowed" and "forbidden" directions for cosmic ray particles in the geomagnetic dipole were determined, using the newly devised BUSH differential analyser at MIT, by generalising the earlier treatment of Stormer. Secondly, by an elegant application of Liouville's Theorem, he and Lemaitre showed that for an isotropic cosmic ray flux the intensity at the earth in the allowed direction is the full intensity prevailing outside the geomagnetic field whereas that in the forbidden directions is zero.

This work provided the basis of our understanding of a wide range of cosmic ray geomagnetic effects and led directly to two particularly important results. First, in predicting an EastWest asymmetry in the cosmic ray intensity at low geomagnetic latitudes whose sign depended on whether the primary cosmic rays were positively or negatively charged, it made possible the experimental proof that the primary particles are predominantly of positive charge. Secondly, the calculations of geomagnetic cut-off energies as a function of position in the geomagnetic dipole, which were carried out in great detail by Vallarta and his students, permitted for the first time a determination of the form of the cosmic ray energy spectrum in the geomagnetically sensitive region. Subsequently, the use of Liouville's Theorem, pioneered in this context by Lemaitre and Vallarta, has been extended beyond the field of cosmic rays to the general case of charged particle motion in magnetic fields of all kinds, whether they be laboratory accelerators, plasma containment machines or situations where particles are accelerated or trapped in the naturally occurring magnetic fields of a wide variety of astronomical objects.

During the course of his lifetime Vallarta contributed notably to the prestige and advancement of science and learning generally in Mexico. $\mathrm{He}$ occupied a number of important posts in education and the administration of science, both in that country and in the wider international scene. In particular, he was inter alia and at various times President of the Mexican National Institute of Scientific Investigation, Member of the National Commission for Nuclear Energy, President of the Latin American Council for Cosmic Ray Studies, Member of the International Commission of Weights and Measures, Sub-secretary for Public Education for Mexico City, President of the Institute for Mexican Cultural Relations in North America and Chairman of the Scientific Council of the International Centre for Theoretical Physics in Trieste. He was the recipient of many academic honours in Mexico, Latin America and elsewhere. These included membership of the Pontifical Academy of Sciences, the Colegio Nacional of Mexico, and the American Academy of Arts and Sciences. In 1952 he was appointed a Knight of the French Legion of Honour.

Manuel Vallarta was outstanding in his generation and for many years he has been a familiar figure to successive generations of cosmic ray researchers. His perceptive and penetrating questions will be missed at future meetings and for all who knew him personally his death represents the loss of a good and kindly friend. $\mathrm{He}$ is survived by his wife Maria Luisa.

H. Elliot 